\title{
Conformational preferences of fluorine-containing agrochemicals and their implications for lipophilicity prediction
}

\author{
Daniela Rodrigues Silva ${ }^{\ddagger}$, Joyce K. Daré ${ }^{\ddagger}$ and Matheus P. Freitas*
}

\author{
Full Research Paper \\ Address: \\ Department of Chemistry, Federal University of Lavras, 37200-900, \\ Lavras-MG, Brazil \\ Email: \\ Matheus P. Freitas* - matheus@ufla.br \\ * Corresponding author $\ddagger$ Equal contributors \\ Keywords: \\ dipole moment; fluorinated compounds; gauche effect; herbicides; \\ $\log P$
}

\author{
Beilstein J. Org. Chem. 2020, 16, 2469-2476. \\ https://doi.org/10.3762/bjoc. 16.200 \\ Received: 30 May 2020 \\ Accepted: 23 September 2020 \\ Published: 05 October 2020 \\ This article is part of the thematic issue "Organo-fluorine chemistry V". \\ Guest Editor: D. O'Hagan \\ (C) 2020 Silva et al.; licensee Beilstein-Institut. \\ License and terms: see end of document.
}

\begin{abstract}
Molecular polarity governs lipophilicity, which in turn determines important agrochemical and environmental properties, such as soil sorption and bioconcentration of organic compounds. Since the C-F bond is the most polar in organic chemistry, the orientation of fluorine substituents originating from the rotation around $\mathrm{C}-\mathrm{C}(\mathrm{F})$ bonds should affect the polarity and, consequently, the physicochemical and biological properties of fluorine-containing agrochemicals. Accordingly, this study aims to determine the most likely conformers of some fluorine-containing agrochemicals and to correlate their molecular dipole moments with the respective $n$-octanol/water partition coefficients $(\log P)$, in order to investigate the dependence of the lipophilicity with the molecular conformation.
\end{abstract}

\section{Introduction}

Whilst in the last years the agrochemical industry has encountered a period of downturn affected by new regulations, low crop prices, biochemical resistance, among other variables, recent events have shown signs of recovery [1]. Currently, the agrochemical industry focuses on introducing new efficient and more environmentally friendly products, that attend the new regulation requirements, for replacing those agrochemicals that were banned due to either their hazard or inefficiency in fighting persistent weeds and pathogens [1]. However, the process for designing, developing, and introducing new agrochemicals to the market is considerably challenging, since it involves many steps and the optimization of a range of properties. Furthermore, it is also an expensive and time-consuming procedure [2].

Fluorination is a common strategy employed as part of the optimization process during the design of new chemical compounds, which includes the modulation of a variety of proper- 
ties such as lipophilicity, biological half-life, and biosorption $[3,4]$. This role helps in explaining the expressive amount of fluorine-containing agrochemical candidates (around 30\%) as well as pharmaceuticals (around 20\%) [5,6]. In this sense, the chemistry of fluorine-containing compounds has been extensively investigated in order to better understand the effects of fluorination on conformation, membrane permeation, pharmacokinetic properties, among other parameters [7].

From a conformational analysis point of view, the fluorine atom presents minimal steric effects; on the other hand, due to its high electronegativity, the $\mathrm{C}-\mathrm{F}$ bond is highly polarized, which characterizes it as a site for electrostatic and hyperconjugative interactions [8]. Additionally, Juaristi and Notario [9] and O'Hagan and co-workers [10] have highlighted the crucial role of hyperconjugative interactions involving the fluorine lone pair in explaining the chemical behavior of organofluorine molecules and their unusual physicochemical properties. Lastly, Müller [11] explained that these features along with fluorine's strict monovalent binding mode and little polarizability, when covalently bound, guarantee fluorination the well-known ability of modulating physicochemical properties.

Although the stereochemical effects of fluorination, responsible for specific interactions and conformational preferences of several groups of compounds, have become increasingly well understood [12], their direct implication on physicochemical properties has not been fully investigated yet. The orientation of fluorine substituents originated from the rotation of fluorinecontaining $\mathrm{C}-\mathrm{C}$ bonds should affect the polarity and, therefore, the physicochemical and biological properties of organofluorine compounds. However, there is a lack of studies that explain how these well-known conformational effects directly alter macroscopic observed properties, such as lipophilicity [13]

Accordingly, the main goal of this work is to investigate the relationship between lipophilicity and molecular conformation on a set of organofluorine agrochemicals. To this end, this study has been divided in two parts. First, we have analyzed the conformational equilibrium of penoxsulam (I, Figure 1). This compound has a 1,2-disubstituted ethane motif that could adopt three main staggered conformations, namely $\mathbf{I}_{\mathbf{g g}}, \mathbf{I}_{\mathbf{a g}}$ and $\mathbf{I}_{\mathbf{g a}}$ ( $\mathrm{g}=$ gauche and $\mathrm{a}=$ anti ; see Figure 1), thus we have explored the intramolecular interactions governing its conformational preferences. It is worth mentioning that $\mathbf{I}_{\mathbf{g g}}$ has two gauche relationships between $\mathrm{C}-\mathrm{F}$ and $\mathrm{C}-\mathrm{O}$ bonds, which is stabilized by $\sigma_{\mathrm{CH}} \rightarrow \sigma_{\mathrm{CF} / \mathrm{CO}}$ hyperconjugative interactions [14]. Second, we have searched for the implications of the relative conformational stabilities for $\log P$ prediction, the most common parameter employed to describe lipophilicity. It has been previously established that the lipophilicity of a compound depends greatly on the overall molecular polarity [15], which is often expressed as the molecular dipole moment $(\mu)$. In turn, the orientation of polar bonds also influences the overall polarity of an organic molecule, as above mentioned. Therefore, this work also seeks to assess a correlation between calculated $\mu$ values and experimental $\log P$ measures, in order to unveil the dependence of lipophilicity with molecular conformation.

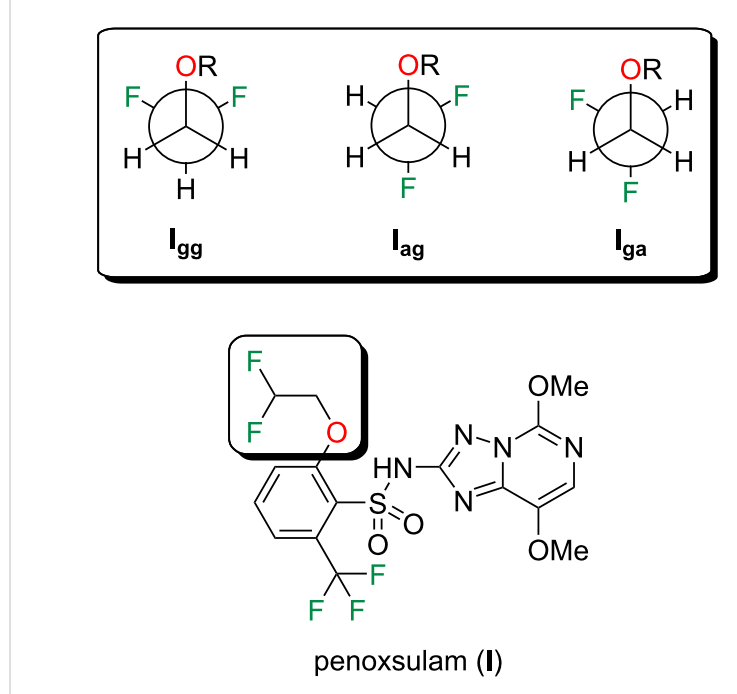

Figure 1: Chemical structure of penoxsulam (I) and the main stag gered conformations along the two $\mathrm{F}-\mathrm{C}-\mathrm{C}-\mathrm{O}$ torsional angles (i.e., $\mathbf{I}_{\mathbf{g g}}$ $\mathrm{I}_{\mathrm{ag}}$, and $\mathrm{I}_{\mathrm{ga}} ; \mathrm{g}=$ gauche and $\mathrm{a}=$ anti).

\section{Results and Discussion Conformational analysis of penoxsulam}

Given the high degree of freedom in the chemical structure of penoxsulam (I), the conformational analysis started with a Monte Carlo conformational search at the $\omega$ B97X-D/6$31 \mathrm{G}(\mathrm{d}, \mathrm{p})[16,17]$ level of the density functional theory (DFT). The global energy minimum conformation was then re-optimized in a higher level of theory, $\omega \mathrm{B} 97 \mathrm{X}-\mathrm{D} / 6-311++\mathrm{G}(\mathrm{d}, \mathrm{p})$ $[16,18]$, resulting in conformer $\mathbf{I}_{\mathbf{a g}}$ (Figure 2). This conformer has one fluorine atom in an anti-orientation and the other one in a gauche-orientation relative to the vicinal oxygen atom (pointing towards the amine hydrogen atom). To evaluate the other possible conformations along the 1,2-disubstituted ethane motif, the $\mathrm{C}-\mathrm{C}(\mathrm{F})$ bond was rotated to additionally obtain conformers $\mathbf{I}_{\mathbf{g g}}$ and $\mathbf{I}_{\mathbf{g a}}$, and the corresponding geometries were then optimized. The resulting geometries and relative conformational energies are summarized in Figure 2.

At first, we observe that the overall geometry is quite similar among the three conformers. Only for $\mathbf{I}_{\mathbf{g a}}$, where the gauche fluorine atom points to the opposite direction of the amine group, the triazole ring was farther away from the 1,2-disubstituted ethane moiety. Note that the gas-phase relative conforma- 


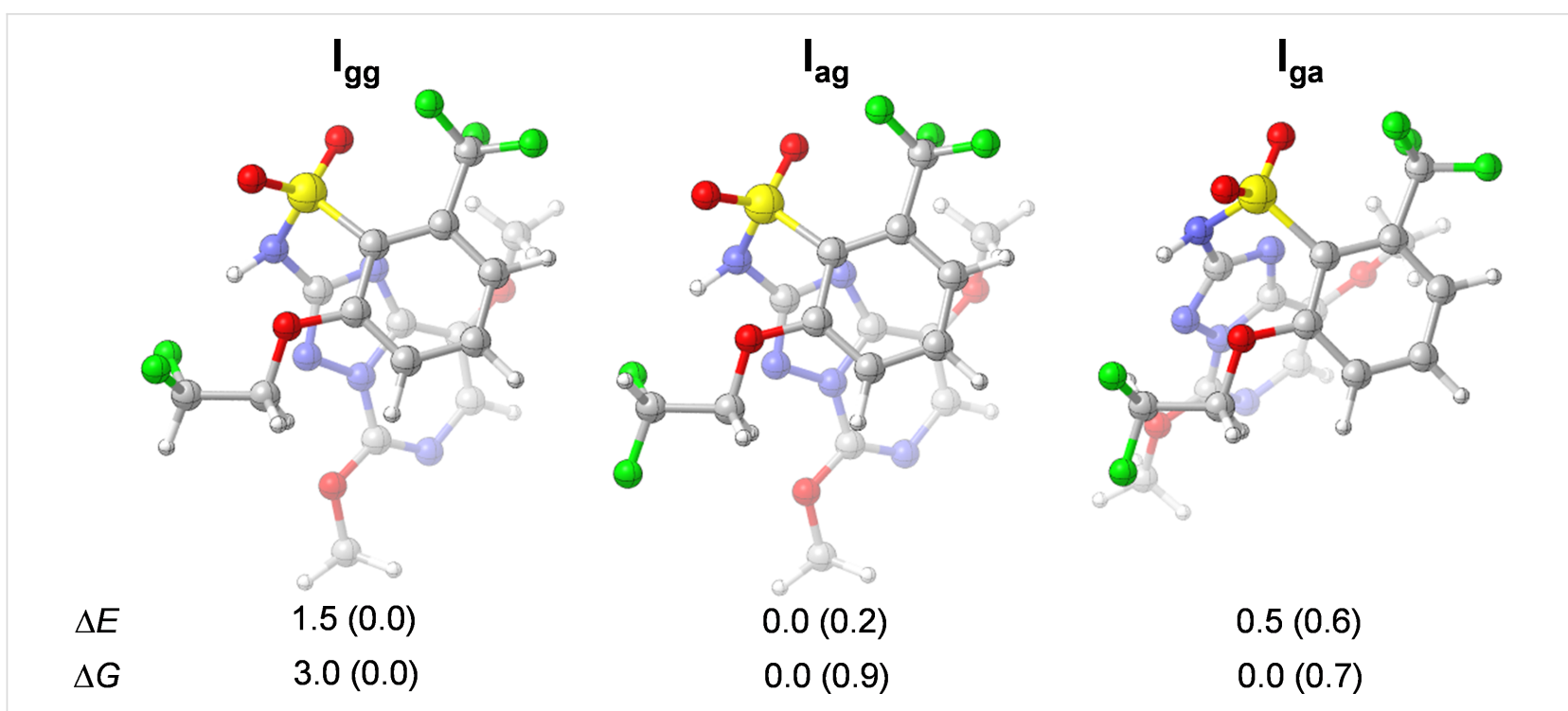

Figure 2: Optimized structures of conformers $\mathbf{I}_{\mathrm{gg}}$ (left), $\mathbf{I}_{\mathrm{ag}}$ (middle), and $\mathbf{I}_{\mathrm{ga}}$ (right), along with the relative electronic and Gibbs free energies (in $\mathrm{kcal} \mathrm{mol}{ }^{-1}$ ) in the gas phase and in water solution (in parentheses), computed at the $\omega B 97 X-D / 6-311++G(d, p)$ level of theory.

tional energy $\Delta E$ increases, i.e., becomes less stabilizing, in the order $\mathbf{I}_{\mathrm{ag}}<\mathbf{I}_{\mathbf{g a}}<\mathbf{I}_{\mathbf{g g}}$. The difference in energy between $\mathbf{I}_{\mathrm{ag}}$ and $\mathbf{I}_{\mathbf{g a}}$ is somehow small $\left(0.5 \mathrm{kcal} \mathrm{mol}^{-1}\right)$, and these conformers are equally stable according to the relative Gibbs free energy $\Delta G$ (Boltzmann populations of $50 \%$ and $49 \%$, respectively). The inclusion of an implicit polar solvent (e.g. water), however, decreases the difference in energy among conformers and $\mathbf{I}_{\mathbf{g g}}$ becomes the most stable conformer in solution, i.e., a double gauche effect takes place (see data in parentheses in Figure 2). This is not surprising, since $\mathbf{I}_{\mathbf{g g}}$ has the highest dipole moment (data shown in the next section) and is naturally more stabilized by polar solvents. Therefore, further analysis will consider the gas phase, since in this way we are accounting for the intrinsic intramolecular interactions without the influence of solvent as an external factor.

To better understand the relative conformational stabilities, we performed a numerical experiment in which the $\mathrm{C}-\mathrm{C}(\mathrm{F})$ bond is rotated from conformer $\mathbf{I}_{\mathrm{ag}}$ keeping other geometrical parameters fixed. In this way, we can specifically investigate the intramolecular interactions governing conformational preferences in the 1,2-disubstituted ethane motif. Furthermore, we decomposed the conformational energy along rotation around the $\mathrm{C}-\mathrm{C}(\mathrm{F})$ bond within the framework of the natural bond orbital (NBO) analysis [19] into the Lewis $\left(\Delta E_{\mathrm{L}}\right.$, which accounts for classical interactions) and non-Lewis $\left(\Delta E_{\mathrm{NL}}\right.$, which accounts for delocalization energy) contributions (Figure 3). Note that all energy terms are represented relative to the conformation with the $\varphi_{\mathrm{O}-\mathrm{C}-\mathrm{C}-\mathrm{H}}$ torsional angle of $0^{\circ}$, thus positive values mean that the energy becomes less stabilizing and negative values mean that the energy becomes more stabilizing.

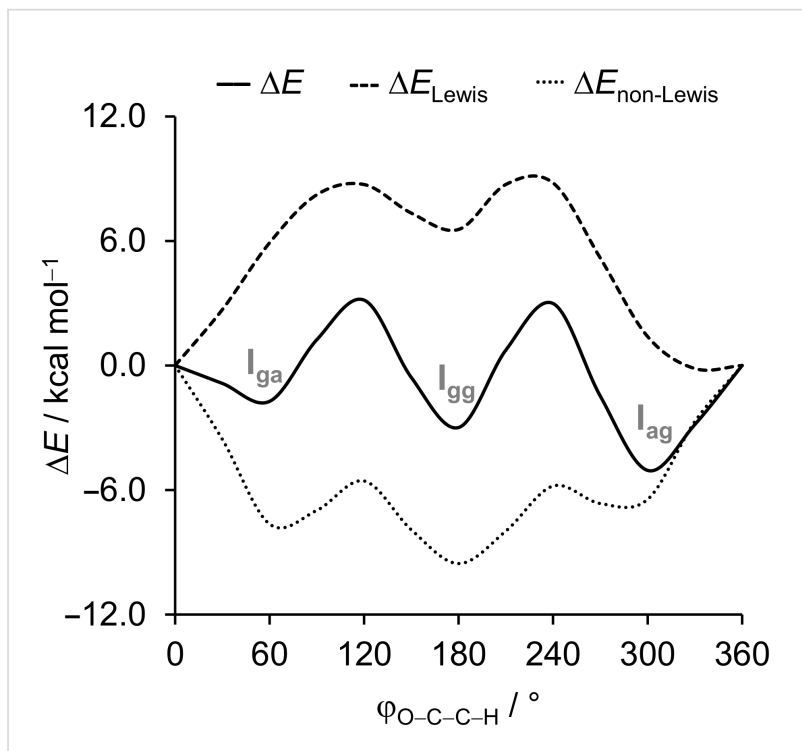

Figure 3: Energy profile for the rotation around the $\mathrm{C}-\mathrm{C}(\mathrm{F})$ bond and

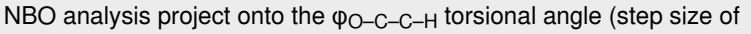
$30^{\circ}$ ) at the $\omega \mathrm{B} 97 \mathrm{X}-\mathrm{D} / 6-311 \mathrm{G}(\mathrm{d}, \mathrm{p})$ level of theory.

From Figure 3, it can be observed that conformer $\mathbf{I}_{\mathbf{g g}}$ is the most stabilized by the $\Delta E_{\mathrm{NL}}$ term, which can be attributed to the stabilizing interactions featured in the gauche effect [14,20], due to the gauche arrangement along the two $\mathrm{F}-\mathrm{C}-\mathrm{C}-\mathrm{O}$ pathways. The charge transfer from the filled $\sigma_{\mathrm{CH}}$ orbital to the empty $\sigma^{*} \mathrm{CF}$ or $\sigma^{*} \mathrm{CO}$ orbitals amounts to $4.6 / 4.5$ and $3.3 \mathrm{kcal} \mathrm{mol}^{-1}$, respectively, which are more stabilizing than the corresponding $\sigma_{\mathrm{CF} / \mathrm{CO}} \rightarrow \sigma^{*} \mathrm{CO} / \mathrm{CF}$ and $\mathrm{n}_{\mathrm{F} / \mathrm{O}} \rightarrow \sigma^{*} \mathrm{CO} / \mathrm{CF}$ in the anti-orientation (Table 1). Note that the $\mathrm{n}_{\mathrm{F}} \rightarrow \sigma^{*} \mathrm{CO}$ charge transfer is slightly more stabilizing than the $\sigma_{\mathrm{CF}} \rightarrow \sigma^{*} \mathrm{CO}$, which 
is in agreement with the findings of Juaristi and Notario [9], and O'Hagan and co-workers [10]. Besides, there is also an interaction between the fluorine electron lone pair $\mathrm{n}_{\mathrm{F}}$ and the $\sigma^{*} \mathrm{NH}$ orbital of the amine group (of $3.2 \mathrm{kcal} \mathrm{mol}^{-1}$, see Table 1). $\mathbf{I}_{\mathbf{g a}}$ also experiences this stabilizing hydrogen bond-like intramolecular interaction $\left(\mathrm{n}_{\mathrm{F}} \rightarrow \sigma_{\mathrm{NH}}\right.$ of $2.8 \mathrm{kcal} \mathrm{mol}^{-1}$, see Table 1$)$. Yet, conformer $\mathbf{I}_{\mathbf{g g}}$ is not the global energy minimum. This is surprising, because all-gauche conformations in fluoropropanediol are strongly preferred [21], while the double gauche effect in difluoroethylamine and its hydrochloride salt stabilizes the gg over ag conformations [22]. Therefore, $\mathbf{I}_{\mathbf{a g}}$ is the global energy minimum because it experiences a more stabilizing $\Delta E_{\mathrm{L}}$ term. Among the three conformers, $\mathbf{I}_{\mathbf{g g}}$ has the least stabilizing $\Delta E_{\mathrm{L}}$ energy, and this can be ascribed to the closer proximity between the $\mathrm{F}$ and $\mathrm{O}$ electronegative atoms. Thus, the least stabilizing $\Delta E_{\mathrm{L}}$ term overcomes the stabilization from hyperconjugation interactions $\left(\Delta E_{\mathrm{NL}}\right)$, and classical electrostatic and steric interactions are the main factors governing conformational preferences of penoxsulam (I).

It is worth mentioning that the structure of penoxsulam in the biological environment is already known in the literature [23] and, accordingly, it differs from the energy minimum conformations computed in this work. However, a conformational search in the gas phase, as performed herein, is necessary to fully understand the intramolecular interactions and to establish the correlation between $\mu$ and $\log P$, since this physicochemical property does not depend on the geometry of penoxsulam inside a biological receptor.

\section{Effect of molecular conformation on $\log P$}

Herein, we aim at evaluating the correlation of molecular conformation with lipophilicity, described in terms of the $n$-octanol/water partition coefficient $-\log P$, through molecular dipole moment $(\mu)$. The molecular dipole moment, $\mu$ is a relatively simple parameter that can inform on subtle intramolecular interactions that favor one structural arrangement over another, as previously mentioned. Therefore, by using a weighted average $\mu$ over the most likely conformations to correlate with experimental $\log P$, one can assess the dependence of $\log P$ with molecular conformation.

Accordingly, a consistent set of fluorine-containing agrochemicals (Figure 4) with experimentally available $\log P$ data was selected from a single database [24], which comprises: penoxsulam (I), pyroxsulam (II), cloransulam-methyl (III), flumioxazin (IV), fluroxypyr-1-methylheptyl ester (V), ethalfluralin (VI), and trifluralin (VII). The data set contains compounds without rotatable $\mathrm{C}-\mathrm{C}(\mathrm{F})$ bonds (III-V), with a rotatable $\mathrm{C}-\mathrm{C}(\mathrm{F})$ bond that does not generate different conformers (II, VI, and VII), and with a rotatable $\mathrm{C}-\mathrm{C}(\mathrm{F})$ bond that generates<smiles>COc1ncc(OC)n2nc(NS(=O)(=O)c3c(OCC(F)F)cccc3C(F)(F)F)nc12</smiles>
penoxsulam (I)<smiles>CCOc1nc(F)cc2nc(S(=O)(=O)Nc3c(Cl)cccc3C(=O)OC)nn12</smiles>

cloransulam-methyl (III)<smiles>CCCCCCC(C)OC(=O)COc1nc(F)c(Cl)c(N)c1Cl</smiles>

fluroxypyr-1-methylheptyl ester (V)

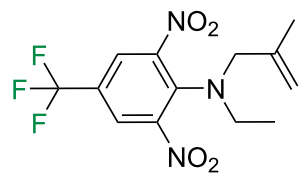

ethalfluralin (VI)<smiles>COc1cc(OC)n2nc(NS(=O)(=O)c3c(C(F)(F)F)ccnc3OC)nc2n1</smiles>

pyroxsulam (II)<smiles>C#CCN1C(=O)COc2cc(F)c(N3C(=O)C4=C(CCCC4)C3=O)cc21</smiles>

flumioxazin (IV)

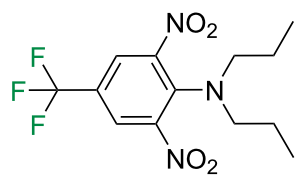

trifluralin (VII)
Figure 4: Chemical structure of the agrochemicals I-VII analyzed herein.

Table 1: Second order perturbation energy $E(2)$ of the main hyperconjugation interactions (in kcal mol-1) computed at the $\omega B 97 X-D / 6-311 G(d, p)$ level of theory.

\begin{tabular}{llllllll} 
Conf. & $\sigma_{\mathrm{CH}} \rightarrow \sigma_{\mathrm{CF}}^{*}$ & $\sigma_{\mathrm{CH}} \rightarrow \sigma_{\mathrm{CO}}^{*}$ & $\sigma_{\mathrm{CO}} \rightarrow \sigma_{\mathrm{CF}}^{*}$ & $\sigma_{\mathrm{CF}} \rightarrow \sigma_{\mathrm{CO}}^{*}$ & $\mathrm{n}_{\mathrm{F}} \rightarrow \sigma_{\mathrm{CO}}^{*}$ & $\mathrm{n}_{\mathrm{O}} \rightarrow \sigma^{*} \mathrm{CF}$ & $\mathrm{n}_{\mathrm{F}} \rightarrow \sigma^{*}{ }_{\mathrm{NH}}$ \\
\hline $\mathbf{I}_{\mathbf{g g}}$ & $4.6 / 4.5$ & 3.3 & - & - & - & - & 3.2 \\
$\mathbf{I}_{\mathbf{a g}}$ & 4.7 & - & 1.5 & 1.5 & 1.8 & 0.8 & 2.8 \\
$\mathbf{I}_{\mathbf{g a}}$ & 4.3 & - & 1.7 & 1.4 & 1.6 & 0.8 & -
\end{tabular}


different conformers (I). The $\mu$ values for all herbicides were computed through theoretical calculations (see computational details section) and are presented in Table 2 along with their respective experimental $\log P$ data.

Table 2: Experimental $\log P$, dipole moment $(\mu$, in $\mathrm{Db})$, and predicted $\log P$ of agrochemicals I-VII.

\begin{tabular}{llll} 
Compd. & $\log P^{\mathrm{a}}$ & $\mu^{\mathrm{b}}$ & milog $P^{\mathrm{c}}$ \\
\hline $\mathbf{I}_{\mathbf{g g}}[\mathbf{0 . 0 1 ]}$ & -0.60 & 11.56 & 2.74 \\
$\mathbf{I}_{\mathbf{a g}}[\mathbf{0 . 5 0 ]}$ & -0.60 & 9.61 & 2.74 \\
I ga $_{\text {[0.49] }}$ & -0.60 & 9.50 & 2.74 \\
II & -1.01 & 7.24 & 1.44 \\
III & 1.12 & 7.76 & 3.09 \\
IV & 2.55 & 4.27 & 2.12 \\
V & 5.04 & 0.68 & 5.43 \\
VI & 5.11 & 2.32 & 4.28 \\
VII & 5.27 & 2.85 & 4.47 \\
\hline
\end{tabular}

${ }^{a}$ Experimental $\log P$ obtained from the Dow AgroSciences database [24]; b dipole moments computed at the $\omega B 97 X-D / 6-311++G(d, p)$ level of theory, see computational section for details; ${ }^{C}$ predicted log $P$ calculated in the Molinspiration Cheminformatics server [25]

Penoxsulam (I) has a rotatable $\mathrm{C}-\mathrm{C}(\mathrm{F})$ bond (as analyzed in the previous section) and, consequently, has the dependence of the molecular dipole moment $\mu$ with the rotation around this bond. It is well-known that $\mu$ is influenced by two main factors: the molecular dimensions and the electron distribution [26]. Thus, a different $\mu$ was calculated for each of the three staggered conformers of $\mathbf{I}$ and a weighted average $\mu$ was obtained from the calculated $\mu$ of the three conformers $\mathbf{I}_{\mathbf{g g}}, \mathbf{I}_{\mathbf{a g}}$, and $\mathbf{I}_{\mathbf{g a}}$. Then, the calculated $\mu$ values were plotted against the experimental $\log P$ (Figure 5a) in order to quantitatively analyze the correlation between the two parameters. The resulting linear regression coefficient $\left(\mathrm{r}^{2}\right)$ was 0.86 , which can be considered a suitable correlation coefficient. A hypothesis test for the significance of the observed correlation, based on the $p$-value (at a significance level of $95 \%, \alpha=0.05$ ), was also carried out. A $p$-value of 0.00264 was obtained, which is much smaller than the critical value of 0.05 . Therefore, the null hypothesis (that considers the correlation coefficient as 0 ) is rejected, which reinforces the dependence of lipophilicity on the total molecular polarity.

In another attempt to demonstrate the importance of $\mu$ (a conformational dependent parameter) for estimating $\log P$, we employed the Molinspiration Cheminformatics tool [25] to predict $\log P$, and the results are displayed in Table 2. The predicted outcomes were also plotted against the experimental values (see Figure $5 \mathrm{~b}$ ). Most tools for predicting physicochemical proper-

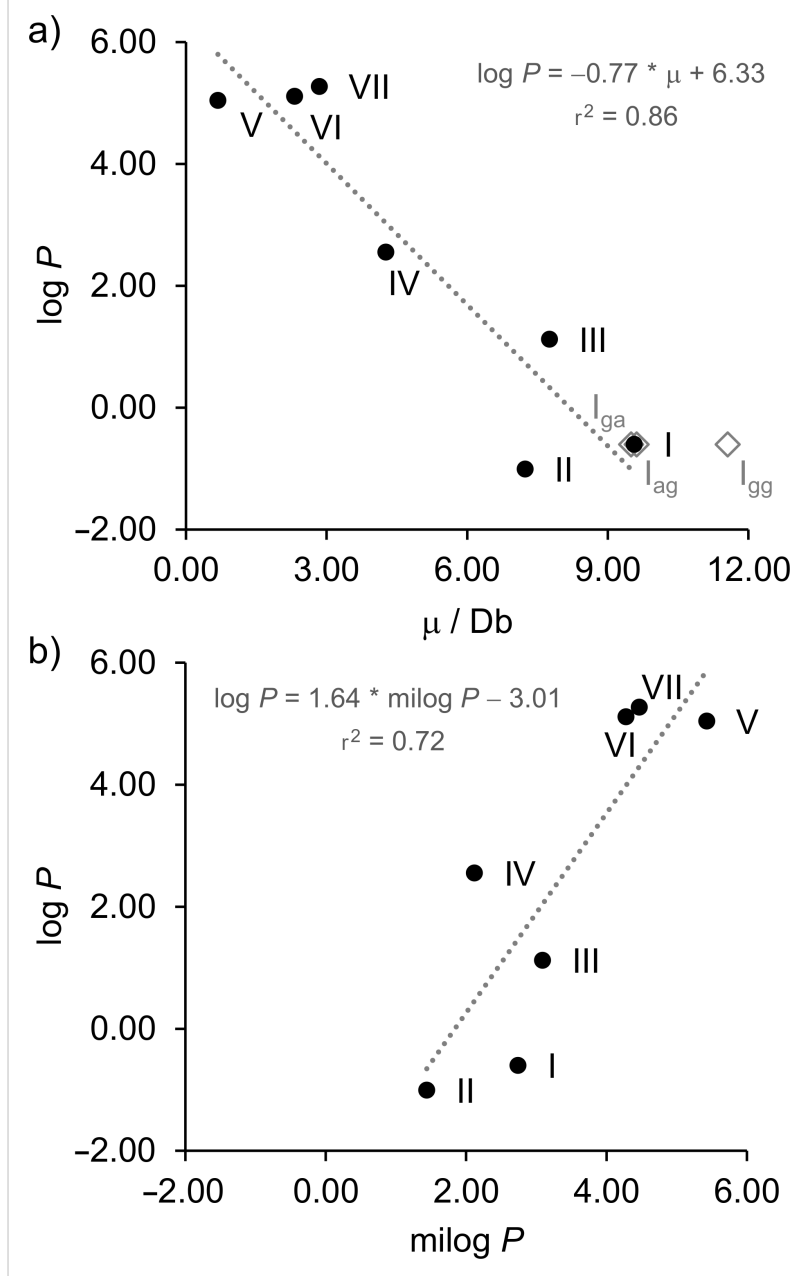

Figure 5: Correlation between the experimental $\log P$ of agrochemicals I-VII and a) dipole moment (for $\mathbf{I}, \mu$ is used as a weighted average of the conformers $\mathbf{I}_{\mathbf{g g}}, \mathbf{I}_{\mathbf{a g}}$, and $\left.\mathbf{I}_{\mathbf{g a}}\right)$, and b) predicted $\log P$ $($ milog $P$ ).

ties are based on the additive contributions of polarity from atoms or chemical groups instead of considering the overall molecular polarity $(\mu)$ [27]. The predictive ability of these methods for compounds with higher structural complexity have been questioned in the literature [28]. Indeed, the obtained $\mathrm{r}^{2}(0.72)$ exhibits a considerably higher discrepancy than that correlation obtained from $\mu$ when compared to the optimal value of 1 . A linear regression of experimental $\log P$ against calculated $\log P$ values obtained from another source (the ChemSketch module of the ACD/Labs program) yields a similar result $\left(r^{2}=0.71\right.$, see Figure S1 in Supporting Information File 1). Moreover, from Figure 5b, due to the high slope and the resulting intercept, one can assume the existence of a systematic error associated with the prediction of $\log P$. This finding reinsures the issues with additive methods for predicting lipophilicity of complex structures as those analyzed herein. 
Nevertheless, a reservation should be considered for small organofluorine compounds, for which well-parameterized models for $\log P$ prediction are usually available.

Regarding the use of calculated molecular dipole moments as a descriptor of lipophilicity for small molecules, a more detailed analysis is required. Accordingly, a series of structurally simpler organofluorine compounds were retrieved (Figure 6), all from the same source [29], and a similar computational routine was carried out (see computational details section for a full description).

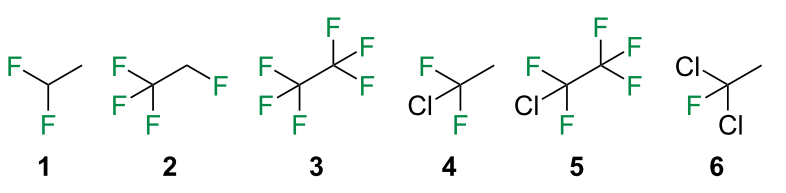<smiles>FC(F)(Cl)C(F)(F)Cl</smiles><smiles>FC(F)(F)C(F)(F)Cl</smiles>

8<smiles>FC(F)(Cl)C(F)(Cl)Cl</smiles>

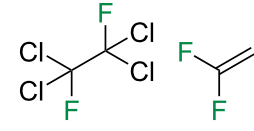

10
Figure 6: Chemical structure of the compounds 1-11 analyzed herein

Compounds 7, 9, and $\mathbf{1 0}$ have the dependence of the molecular dipole moment $\mu$ with the rotation around the $\mathrm{C}-\mathrm{C}$ bond. The correlation plots between the experimental $\log P$ of compounds 1-11 and a) dipole moment and b) predicted $\log P$ are shown in Figure 7.

From Figure 7a one can observe an $\mathrm{r}^{2}$ value of 0.53 , which indicates a rough correlation between $\mu$ and $\log P$. However, when applying the same hypothesis test, as for the first data set, a $p$-value of 0.0115 was obtained, which suggests that, although smaller than the first correlation, there is also a dependence between the calculated dipole moment and lipophilicity for small molecules. The considerably lower correlation may be explained by the fact that, in a small molecule, subtle structural changes strongly influence the overall molecular dipole and, sometimes, the introduction of a polar bond in a molecule decreases the overall molecular dipole moment. For instance, carbon tetrafluoride has four polar bonds, but it is apolar, while the other fluorinated methanes are all polar. Thus, the use of calculated molecular dipole moments as descriptors for lipophilicity in these small organofluorines should be used with caution. On the other hand, Figure $7 \mathrm{~b}$ reveals a satisfactory correlation between the predicted and experimental values of $\log P$, which reinforces that for simple molecules there are well-
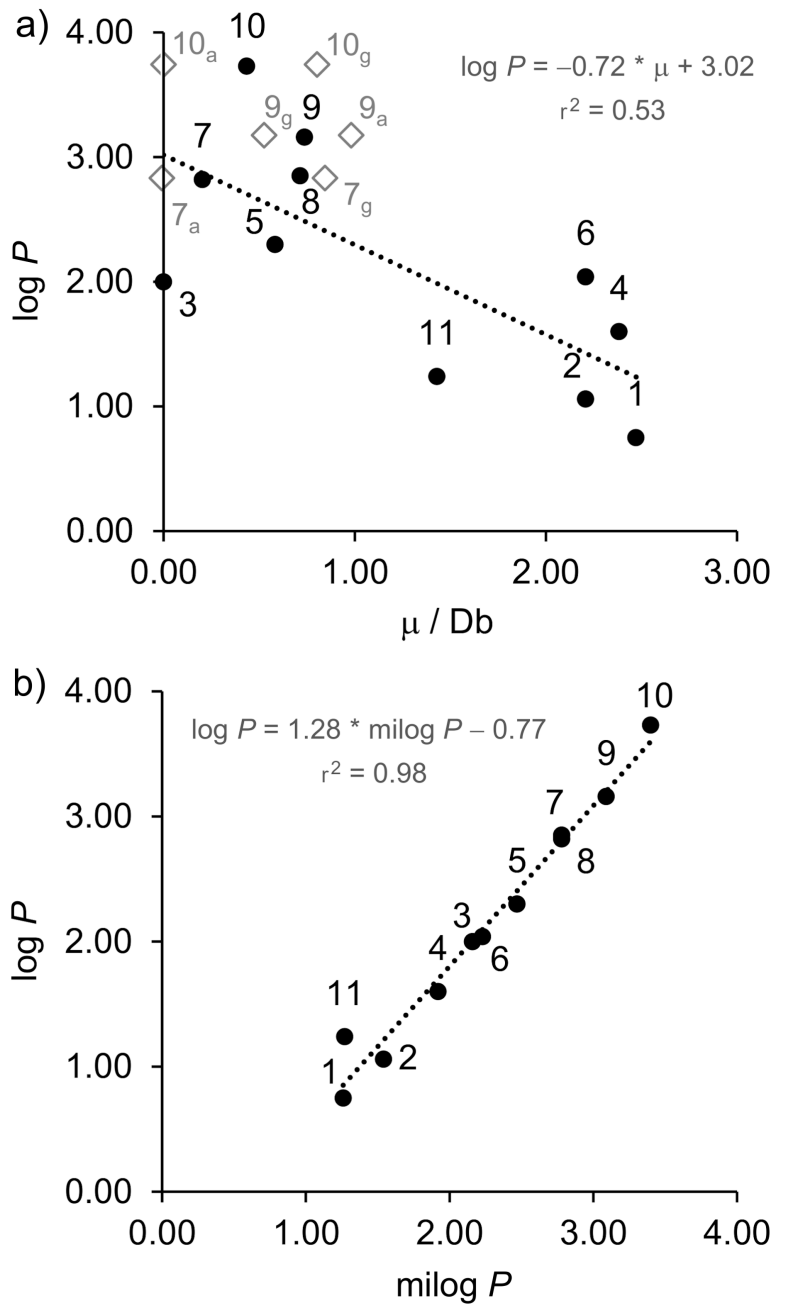

Figure 7: Correlation between the experimental $\log P$ of compounds 1-11 and a) dipole moment (for 7, 9, and 10, $\mu$ is used as a weighted average of the gauche and anti-conformers), and b) predicted $\log P$ $($ milog $P$ ).

parameterized models for $\log P$ prediction, in spite of the remarkable systematic error.

\section{Conclusion}

In summary, the overall molecular polarity is influenced not only by the nature of the substituent group (as considered by additive techniques of prediction), but also by the orientation of the neat molecular dipole moment vector. In this sense, methods that ignore such influences result in reduced accuracy when predicting physicochemical properties of complex structures, such as the herbicides presented herein. Taking into account the correlation between lipophilicity and molecular conformation contributes to rationalize the effect of fluorine introduction on lipophilicity. Furthermore, the use of the molecular dipole moment that considers information on the molecular conforma- 
tion, as presented herein, is a simple and straightforward parameter that can be valuable as a descriptor in quantitative structure-property relationships (QSPR). This could contribute significantly in studies involving organofluorine agrochemicals, for example, towards modeling herbicidal activity, and/or for environmental risk assessment.

\section{Computational Details}

The conformational search of agrochemicals I-VII was performed at the $\omega \mathrm{B} 97 \mathrm{X}-\mathrm{D} / 6-31 \mathrm{G}(\mathrm{d}, \mathrm{p})[16,17]$ level of theory using the Spartan'18 software [30]. The lowest energy minimum conformation of each compound was then reoptimized and the dipole moment determined using a higher level of theory, $\omega \mathrm{B} 97 \mathrm{X}-\mathrm{D} / 6-311++\mathrm{G}(\mathrm{d}, \mathrm{p})[16,18]$, in the Gaussian 09 software [31]. The geometries and dipole moments for compounds 1-11 were calculated at the same level, which has been successfully applied to predict the conformational energies of other fluorine-containing compounds [32-34]. Frequency calculations were performed to confirm that the optimized geometries were true energy minima (no imaginary frequency) and to estimate thermodynamic energies, at $298.15 \mathrm{~K}$. Solvent effects were accounted for by geometry optimization using the integral equation formalism variant of the polarizable continuum model (IEFPCM) [35]. Insights into the intramolecular interactions governing conformational preferences were obtained through the natural bond orbital (NBO) analysis $[19,36]$. The predicted $\log P$ was calculated using the Molinspiration Cheminformatics tool [25] and molecular structures were illustrated using CYLview [37].

\section{Supporting Information}

\section{Supporting Information File 1}

Additional linear correlation, main conformers from the Monte Carlo conformational search, Cartesian coordinates and energies of the conformers of agrochemicals I-VII and compounds 1-11 analyzed herein.

[https://www.beilstein-journals.org/bjoc/content/ supplementary/1860-5397-16-200-S1.pdf]

\section{Funding}

The authors are grateful to the Conselho Nacional de Desenvolvimento Científico e Tecnológico (CNPq, fellowship and scholarship grant numbers 301371/2017-2 and 140955/2017-8, respectively), the Coordenação de Aperfeiçoamento de Pessoal de Nível Superior (CAPES, funding code 001) and the Fundação de Amparo à Pesquisa do Estado de Minas Gerais (FAPEMIG, grant number APQ-00383/15) for financial support.

\section{ORCID ${ }^{\circledR}$ iDs}

Matheus P. Freitas - https://orcid.org/0000-0002-7492-1801

\section{Preprint}

A non-peer-reviewed version of this article has been previously published as a preprint: https://doi.org/10.3762/bxiv.2020.66.v1

\section{References}

1. Phillips, M. W. A. Pest Manage. Sci. 2020, 76, 3348-3356. doi:10.1002/ps.5728

2. Sparks, T. C.; Lorsbach, B. A. Pest Manage. Sci. 2017, 73, 672-677. doi:10.1002/ps.4457

3. Jeffries, B.; Wang, Z.; Felstead, H. R.; Le Questel, J.-Y.; Scott, J. S.; Chiarparin, E.; Graton, J.; Linclau, B. J. Med. Chem. 2020, 63, 1002-1031. doi:10.1021/acs.jmedchem.9b01172

4. Zhou, Y.; Wang, J.; Gu, Z.; Wang, S.; Zhu, W.; Aceña, J. L.; Soloshonok, V. A.; Izawa, K.; Liu, H. Chem. Rev. 2016, 116, 422-518. doi:10.1021/acs.chemrev.5b00392

5. Fujiwara, T.; O'Hagan, D. J. Fluorine Chem. 2014, 167, 16-29 doi:10.1016/j.jfluchem.2014.06.014

6. O'Hagan, D. J. Fluorine Chem. 2010, 131, 1071-1081. doi:10.1016/j.jfluchem.2010.03.003

7. Gillis, E. P.; Eastman, K. J.; Hill, M. D.; Donnelly, D. J.; Meanwell, N. A. J. Med. Chem. 2015, 58, 8315-8359. doi:10.1021/acs.jmedchem.5b00258

8. Hunter, L. Beilstein J. Org. Chem. 2010, 6, No. 38. doi:10.3762/bjoc.6.38

9. Juaristi, E.; Notario, R. J. Org. Chem. 2016, 81, 1192-1197. doi:10.1021/acs.joc.5b02718

10. Keddie, N. S.; Slawin, A. M. Z.; Lebl, T.; Philp, D.; O'Hagan, D. Nat. Chem. 2015, 7, 483-488. doi:10.1038/nchem.2232

11. Müller, K. Chimia 2014, 68, 356-362. doi:10.2533/chimia.2014.356

12. O'Hagan, D. Chem. Soc. Rev. 2008, 37, 308-319. doi:10.1039/b711844a

13. O'Hagan, D.; Young, R. J. Angew. Chem., Int. Ed. 2016, 55, 3858-3860. doi:10.1002/anie.201511055 Angew. Chem. 2016, 128, 3922-3924. doi:10.1002/ange.201511055

14. Buissonneaud, D. Y.; van Mourik, T.; O'Hagan, D. Tetrahedron 2010, 66, 2196-2202. doi:10.1016/j.tet.2010.01.049

15. Huchet, Q. A.; Kuhn, B.; Wagner, B.; Fischer, H.; Kansy, M.; Zimmerli, D.; Carreira, E. M.; Müller, K. J. Fluorine Chem. 2013, 152 , 119-128. doi:10.1016/j.jfluchem.2013.02.023

16. Chai, J.-D.; Head-Gordon, M. Phys. Chem. Chem. Phys. 2008, 10, 6615-6620. doi:10.1039/b810189b

17. Francl, M. M.; Pietro, W. J.; Hehre, W. J.; Binkley, J. S.; Gordon, M. S.; DeFrees, D. J.; Pople, J. A. J. Chem. Phys. 1982, 77, 3654-3665. doi:10.1063/1.444267

18. Krishnan, R.; Binkley, J. S.; Seeger, R.; Pople, J. A. J. Chem. Phys. 1980, 72, 650-654. doi:10.1063/1.438955

19. Glendening, E. D.; Landis, C. R.; Weinhold, F. J. Comput. Chem. 2013, 34, 1429-1437. doi:10.1002/jcc.23266

20. Goodman, L.; Gu, H.; Pophristic, V. J. Phys. Chem. A 2005, 109 , 1223-1229. doi:10.1021/jp046290d

21. Andrade, L. A. F.; Silla, J. M.; Duarte, C. J.; Rittner, R.; Freitas, M. P. Org. Biomol. Chem. 2013, 11, 6766-6771. doi:10.1039/c3ob41207e

22. Silla, J. M.; Duarte, C. J.; Cormanich, R. A.; Rittner, R.; Freitas, M. P. Beilstein J. Org. Chem. 2014, 10, 877-882. doi:10.3762/bjoc.10.84 
23. Lonhienne, T.; Garcia, M. D.; Pierens, G.; Mobli, M.; Nouwens, A.; Guddat, L. W. Proc. Natl. Acad. Sci. U. S. A. 2018, 115, E1945-E1954. doi:10.1073/pnas.1714392115

24. SDS Finder - Dow Safety Data Sheets. https://www.dow.com/en-us/support/sds-finder.html.

25. Molinspiration Cheminformatics 2020; Calculation of Molecular Properties and Bioactivity Score. https://www.molinspiration.com/cgi-bin/properties.

26. Carey, F.; Sundberg, R. Chemical Bonding and Molecular Structure. In Advanced Organic Chemistry: Part A: Structure and Mechanisms, 5th ed.; Springer: New York, NY, USA, 2008; $p 52$.

27. Matter, H.; Barighaus, K.-H.; Naumann, T.; Klabunde, T.; Pirard, B. Comb. Chem. High Throughput Screening 2001, 4, 453-475. doi:10.2174/1386207013330896

28. Mannhold, R.; van de Waterbeemd, H. J. Comput.-Aided Mol. Des. 2001, 15, 337-354. doi:10.1023/a:1011107422318

29. Mackay, D.; Shiu, W.; Ma, K.-C.; Lee, S. Handbook of Physical-Chemical Properties and Environmental Fate for Organic Chemicals, 2nd ed.; CRC Press: Boca Raton, FL, USA, 2006. doi:10.1201/9781420044393

30. Spartan'18, Version 1.3.0; Wavefunction, Inc.: Irvine, CA, USA, 2018.

31. Gaussian 09, Revision D.01; Gaussian, Inc.: Wallingford, CT, 2013.

32. Silla, J. M.; Freitas, M. P. J. Fluorine Chem. 2019, 217, 8-12. doi:10.1016/j.jluchem.2018.10.018

33. Martins, F. A.; Silla, J. M.; Freitas, M. P. Beilstein J. Org. Chem. 2017, 13, 1781-1787. doi:10.3762/bjoc.13.172

34. Andrade, L. A. F.; Freitas, M. P. New J. Chem. 2017, 41, 11672-11678. doi:10.1039/c7nj02463k

35. Tomasi, J.; Mennucci, B.; Cammi, R. Chem. Rev. 2005, 105, 2999-3094. doi:10.1021/cr9904009

36. NBO 6.0; Theoretical Chemistry Institute: University of Wisconsin, Madison, USA, 2013.

37. CYLview, 1.0b; Legault, C. Y.: Université de Sherbrooke, 2009, http://www.cylview.org.

\section{License and Terms}

This is an Open Access article under the terms of the Creative Commons Attribution License (https://creativecommons.org/licenses/by/4.0). Please note that the reuse, redistribution and reproduction in particular requires that the authors and source are credited.

The license is subject to the Beilstein Journal of Organic Chemistry terms and conditions:

(https://www.beilstein-journals.org/bjoc)

The definitive version of this article is the electronic one which can be found at: https://doi.org/10.3762/bjoc. 16.200 